\title{
Pre-Movement Cortico-Muscular Dynamics Underlying Improved Parkinson Gait Initiation after Instructed Arm Swing
}

\author{
Joyce B. Weersink, Silvano R. Gefferie, Teus van Laar, Natasha M. Maurits and Bauke M. de Jong* \\ Department of Neurology, University Medical Center Groningen, University of Groningen, Groningen, \\ The Netherlands
}

Accepted 12 July 2020

\begin{abstract}
.
Background: The supplementary motor area (SMA) is implicated in both motor initiation and stereotypic multi-limb movements such as walking with arm swing. Gait in Parkinson's disease exhibits starting difficulties and reduced arm swing, consistent with reduced SMA activity.

Objective: We tested whether enhanced arm swing could improve Parkinson gait initiation and assessed whether increased SMA activity during preparation might facilitate such improvement.

Methods: Effects of instructed arm swing on cortical activity, muscle activity and kinematics were assessed by ambulant EEG, EMG, accelerometers and video in 17 Parkinson patients and 19 controls. At baseline, all participants repeatedly started walking after a simple auditory cue. Next, patients started walking at this cue, which now meant starting with enhanced arm swing. EEG changes over the putative SMA and leg motor cortex were assessed by event related spectral perturbation (ERSP) analysis of recordings at $\mathrm{Fz}$ and $\mathrm{Cz}$.

Results: Over the putative SMA location (Fz), natural PD gait initiation showed enhanced alpha/theta synchronization around the auditory cue, and reduced alpha/beta desynchronization during gait preparation and movement onset, compared to controls. Leg muscle activity in patients was reduced during preparation and movement onset, while the latter was delayed compared to controls. When starting with enhanced arm swing, these group differences virtually disappeared.

Conclusion: Instructed arm swing improves Parkinson gait initiation. ERSP normalization around the cue indicates that the attributed information may serve as a semi-internal cue, recruiting an internalized motor program to overcome initiation difficulties.
\end{abstract}

Keywords: Arm swing, Parkinson's disease, gait initiation, supplementary motor area, ambulant electroencephalography

\section{INTRODUCTION}

Parkinson's disease (PD) is characterized by a wide spectrum of motor and non-motor symptoms,

\footnotetext{
*Correspondence to: Bauke M. de Jong, MD, PhD, Department of Neurology, University Medical Center Groningen, Hanzeplein 1, P. O. Box 30.001, 9700 RB Groningen, The Netherlands. Tel.: +31 50361 2400; Fax: +31 50361 1707; E-mail: b.m.de.jong@ umcg.nl.
}

in which loss of dopaminergic neurons plays a central causal role [1]. The motor symptoms concern bradykinesia together with either rigidity, rest tremor or both [2]. In gait, bradykinesia is revealed by reduced step length and reduced or absent arm swing [3-5], while the slowness of locomotion may be reinforced by hesitations to start walking. Most disabling is freezing of gait [6], which may not only occur at the onset of walking but is also reflected in the abrupt 
inability to maintain the cyclic pattern of gait. An environmental factor such as the transition to a narrow corridor or doorway may provoke freezing of gait [7-10]. External stimuli, on the other hand, may also help to overcome freezing [11-14]. These circumstances point at a more general feature of higher-order motor dysfunction in PD: the enhanced impact of external stimuli complements the impairment of selfinitiated movement [15-17]. This altered balance between externally and internally driven actions is consistent with 1) the contribution of the normal (pre-)supplementary motor area (SMA) to internally driven action [18-20] and 2) the finding that in PD, this target region of basal ganglia-thalamic circuitry is functionally affected [21-25]. Aside from this SMA contribution to motor initiation, it has a welldescribed role in multi-limb co-ordination [26-30], which is also expressed in human bipedal walking with anti-phase arm swing [31], a movement pattern which is characteristically affected in PD. These basic assumptions laid ground for the present study, in which we aimed to particularly explore the role of arm swing in the initiation of gait by assessing the relation between cerebral activation, muscle activity and the kinematic characteristics of actual movement in both normal and PD-affected gait. A preliminary observation already indicated that forward arm extension accelerates gait initiation in PD [32].

Studying the relation between cerebral and muscle activities during overground walking requires ambulant measurements, which can be done with ambulant electroencephalography (EEG) in combination with electromyography (EMG) of distinct indicator muscles [33-36]. In addition, accelerometer recordings enable demarcation of the onset of locomotion and specific stages of the gait cycle. Analysis of event related spectral perturbations (ERSP) in the EEG enables the assessment of average dynamic changes in power across the broad band frequency spectrum as a function of time relative to gait-related events [37]. Alpha and beta-oscillatory activity play a predominant role in the initiation and modulation of motor activity, with a power decrease (event related desynchronization, ERD) prior to and during movement followed by post-movement rebound (i.e., event related synchronization, ERS) [38-40]. In PD patients, less decrease of beta power in the motor cortex prior to and during movement has been described [41-44], while ERD could be restored by various therapeutic strategies $[44,45]$. Consistent with these PD-associated ERSP effects, we recently found a reduced ERD over the putative SMA in healthy participants when walking without arm swing, mimicking PD gait, compared to walking with arm swing [31]. This ERSP study provided support for the concept that arm swing may reflect an SMA-mediated driving force in gait control. Indeed, the verbal instruction to increase arm swing has been described to normalize gait parameters in PD patients $[46,47]$.

Kinematically, gait initiation concerns the transient period between standing motionless and steady-state walking, which typically takes three steps $[48,49]$. In PD patients, freezing of gait implies that the postural phase is prolonged, with delayed displacement of the centre of gravity between shifting the weight away from the intended swing side and toe-off in the leading limb [50-53]. These kinematical changes are associated with an EMG profile of reduced activation of the tibialis anterior, soleus, vastus lateralis and gastrocnemius muscles $[54,55]$. PD gait abnormalities in the transition phase to steady state walking further include reduced step length and step velocity, increased stride-to-stride variability and prolonged double support phase [56]. These altered gait parameters are related with reduced arm swing in PD [3-5, 57]. Assessing distinct characteristics of actual movement and muscle activity in the lower and upper limbs, with concurrent EEG recordings during gait onset, thus provides an opportunity to specify the relationship between SMA function, arm swing and gait initiation in PD patients, while the comparison with healthy participants may identify disease-related changes in this relationship.

As stated above, the verbal instruction to increase arm swing has been described to normalize gait parameters in PD patients [46, 47]. At cortical level, we hypothesized to find an enhanced contribution of particularly the SMA mediating the instructed arm swing to achieve improved gait initiation. For this reason, while EEG was recorded at 32 sites covering the entire scalp, the recordings over the putative SMA and the midline representation of the legs on the primary motor cortex (M1) were selected for detailed analysis. During continuous gait, both M1 and the SMA are implicated in directly driving the involved muscles [31, 35, 58-67]. The stronger and more widespread connections of the SMA with the motor field of the contralateral cortex, compared to M1 [26, 68, 69], underscores the strong SMA involvement in the coordination of multi-limb movements $[27,31,70]$. The latter is consistent with its involvement in (particularly anticipated) postural correction responses [71]. During voluntary gait initiation, regardless of whether it is cued by a strict instruction or entirely 
internally driven, the SMA is implicated in preparing the sequential order and timing of movements, including the recruitment of embedded motor programs [16, 72-76]. Consistent with such function is the association of reduced SMA activation in PD patients with altered step initiation [77], reduced step length and lost arm swing [25, 78], while a recent meta-analysis of functional neuroimaging studies on gait impairment in PD highlighted reduced SMA activation as one of the most consistent findings [79].

The acquisition of ambulant EEG and four-limb EMG recordings during the preparation and actual initiation of overground walking enables the assessment of functional relationships between the SMA and arm swing in facilitating the onset of gait. Even more insight in such relationships can be obtained by comparing the following three conditions: natural gait initiation in healthy participants and PD patients, together with gait initiation in PD patients following the instruction of enhanced arm swing. By examining dynamic power changes in the EEG recordings over the putative SMA and legs M1, EMG profiles of lower limb muscles, and signals from movement sensors, the effect of gait preparation with enhanced arm swing on the efficacy of gait initiation can be determined. In this way we aimed to test the hypothesis that the instruction to start walking with enhanced arm swing will result in enhanced beta desynchronization over the SMA prior to and during gait initiation, which reflects a restored SMA function, and will consequently facilitate and improve gait initiation in PD patients.

\section{MATERIALS AND METHODS}

\section{Participants}

Nineteen healthy participants (9 males, 10 females) with median age ( \pm interquartile) of 67 $( \pm 12)$ years and 17 PD patients ( 11 males, 6 females; median age $67 \pm 12$ years) with self-reported trouble initiating gait were included in the study. PD patients were assessed in their end-of-dose state to minimize medication effects. During the experiment, they did not experience freezing of gait. All participants were able to walk independently (for PD; Hoehn and Yahr scale: Stage 2-3), had no cognitive problems (for controls and PD median Mini-Mental State Examination (MMSE): 29) and were right handed according to the Annett Handedness scale [80]. The study was executed according to the Declaration of Helsinki
(2013) and approved by the ethical committee of the University Medical Centre Groningen.

\section{Task and experimental set-up}

Participants were instructed to start overground walking for six meters at comfortable speed after hearing an auditory beep. This was repeated 30 times. The first (baseline) condition for both healthy controls and PD patients concerned initiating gait without additional instructions. Such simple instruction to start in a natural fashion was given to avoid confusion. The baseline gait initiation was practiced before the formal onset of recording in order to accommodate with the procedures. After a short resting period, PD patients performed a second condition for which they had to walk with enhanced arm swing over the same trajectory. Now, they were instructed that the same auditory cue meant that they had to start with enhanced arm swing as they stepped. The experimental condition always followed the baseline conditions to avoid that the patients would become highly aware of their reduced arm swing in the natural starting circumstance, which might enhance the risk of blocking natural gait initiation.

During the two sessions, monopolar EEG was recorded using a cap with 32 active $\mathrm{Ag}-\mathrm{AgCl}$ electrodes (EasyCap GmbH, Herrsching, Germany) located according to the international 10-20 system. Using active electrodes, amplification first takes place at the electrode thereby considerably suppressing potential artefacts in the EEG recordings due to cable movements. The ground and reference electrodes were located between Fz and Fpz and between $\mathrm{Cz}$ and $\mathrm{Fz}$, respectively. To further limit artifacts in the EEG, participants were asked to relax face and jaw muscles and to minimize eye blinks and swallowing during data recording. Paired bipolar surface $\mathrm{Ag}-\mathrm{AgCl}$ EMG electrodes were bilaterally placed on the tibial anterior, soleus, rectus femoris and biceps femoris muscles according to the SENIAM (http://www.seniam.org) guidelines, oriented parallel to the muscle fibers with an interelectrode distance of $20 \mathrm{~mm}$. To detect the actual movement onset, heel strike and toe-off during the gait initiation process, tri-axial accelerometers (Compumedics Neuroscan, Singen, Germany) were placed on the medial side of both ankles and over the L3 lumbar spine segment, using Velcro straps. For the trunk accelerometer, orientation of the three accelerometer axes, $\mathrm{X}, \mathrm{Y}$, and $\mathrm{Z}$, when standing in the anatomical position, was medial/lateral, superior/inferior, 
and anterior/posterior, respectively. This recording enabled the detection of, e.g., forward bending preceding gait onset. The EEG, EMG, and accelerometer signals were recorded at a sampling rate of $512 \mathrm{~Hz}$ using a portable amplifier (Siesta, Compumedics Neuroscan, Singen, Germany), synchronized with the audio-video recordings and sent via WIFI to Profusion EEG software (v. 5.0, Compumedics Neuroscan, Singen, Germany) on a laptop and stored for later analysis.

\section{Gait analysis}

Movement onset was determined using the accelerometers placed over the left and right ankles. All participants exhibited a sharp increase in signal amplitude at movement onset which demarcated the actual onset of locomotion (verified with synchronized video). This moment was manually marked as movement onset and it was noted whether participants started with the left or right leg. The time interval between the cue and movement onset was subsequently calculated. Within this interval, the moment of forward bending, which is regarded to represent the onset of anticipatory postural adjustment, could be accurately determined using the z-axis (i.e., anterior-posterior) of the tri-axial accelerometer placed over the L3 lumbar spine segment and was also verified with synchronized video.

The exact time-points of heel strike and toe off were determined by an approach introduced by Sejdic et al. [81], described in more detail by a recent paper of our group [31]. Duration of the double support phase (i.e., the time between heel strike and toe off) and the swing phase (i.e., the time between toe off and heel strike) were calculated for the first four steps. To assess whether PD patients increased their step length when starting with enhanced arm swing, the relative step length of the first four steps was calculated. Kinovea video analysis software (version 0.8.15, http://www.kinovea.org) was used to add grid lines between the two initial contact points (i.e., the heel strikes of the leading and trailing limb) to determine individual mean step length in pixels of the first four steps for both conditions [82]. The leading limb is the leg with which participants start a swing phase first and the trailing limb is the leg that first goes through a stance phase. For each PD patient, mean step length in the condition of starting with enhanced arm swing was divided by mean step length in the condition of starting naturally to determine relative step length of step one to four.

\section{EMG data pre-processing and analysis}

EMG data were pre-processed and analysed using custom made scripts in MATLAB 2015a (The Mathworks, Inc., Natick, Massachusetts, United States). Raw EMG data were high pass $(10 \mathrm{~Hz})$ filtered using a finite impulse response filter, corrected for the delay introduced by the filter and full-wave rectified. Single trial envelopes were calculated for the filtered and rectified EMG activity, and time warped to the individual time interval between auditory beep and the fourth heel strike (HS4) using linear interpolation. After time warping, individual EMG envelopes were expressed as percentage of the mean activity recorded in the time frame during which that individual was standing still $(-4000 \mathrm{~ms}$ until $-2000 \mathrm{~ms}$ before movement onset). Subsequently, individual average envelopes were derived for the leading limb and the trailing limb. For all three conditions, an average EMG envelope of all four lower limb muscles was determined for both leading and trailing limb, which was then smoothed using a $10 \mathrm{~ms}$ moving average window and plotted.

\section{EEG data pre-processing and analysis}

Pre-processing and analyses of EEG data were performed in MATLAB 2015a (The Mathworks, Inc., Natick, MA, USA) using EEGLAB 14_1_2b (sccn.ucsd.edu/eeglab; Delorme and Makeig, 2004). EEG recordings were cut into different task segments and down sampled offline to $256 \mathrm{~Hz}$ to speed up computations. All data were high pass filtered at $1 \mathrm{~Hz}$ using a finite impulse response filter with zero phase shift. Powerline noise was regressed out at 50 and $100 \mathrm{~Hz}$ using the Cleanline technique (nitrc.org/projects/cleanline/). Channels exhibiting substantial artefact were removed using the following criteria: 1) channels with magnitude $<30$ or $>10.000 \mu \mathrm{V}$; 2) channels with kurtosis $>5$ standard deviations from the mean; 3 ) channels uncorrelated with neighbouring channels $(r<0.04)$ for more than $1 \%$ of the total time; 4 ) channels with a standard deviation at least three times higher than other channels. These cut-offs were based on the work of [34]. The next step concerned re-referencing the data to the average of the remaining channels (average 29, SD 1, range 27-31). The EEG channel data from the cleaned data sets were transformed into temporally independent component signals using infomax independent component analysis [83]. EEG data were then epoched from $4000 \mathrm{~ms}$ before until $2000 \mathrm{~ms}$ 
after time of movement onset to ease the identification of movement related artefacts in the following steps. DIPFIT functions within EEGLAB computed an equivalent current dipole model that best explained the scalp topography of each independent component (IC). ICs were removed from the data for further analysis if the projection of the equivalent current dipole model to the scalp accounted for less than $80 \%$ of the IC scalp map variance [84] or if the topography and time-course of the IC were reflective of eye movement artefact $[85,86]$. Because EEG during locomotion is prone to artefact contamination, power spectra, ERSP plots and locations of the equivalent current dipoles of the remaining ICs were inspected for classification as electrocortical sources or muscle sources. According to well-described methods, the most influential ICs regarding these gait related motion artefacts were optimally classified [34, 87, 88]. In our previous study, topographical maps, power spectra and ERSP plots that were attributed to these ICs such as motion artefacts and muscle sources are further specified [31]. All ICs that were not classified as electrocortical sources were removed from the complete continuous dataset, resulting in an average of 15 (SD 3, range 9-18) brain-related ICs per participant used for further analysis. Afterwards, this complete dataset was split into epochs from $4000 \mathrm{~ms}$ before until $2000 \mathrm{~ms}$ after movement onset (i.e., gait initiation) and from the moment of first heel strike (HS1) until $2000 \mathrm{~ms}$ after HS1 (i.e., steps 2-4).

ERSP was calculated for these epochs using the gain model [89], which is the default mode in EEGLAB. Event related spectral power changes were analysed by the ERSP index:

$$
\operatorname{ERSP}(f, t)=\frac{1}{n} \sum_{k=1}^{n}\left(F_{k}(f, t)\right)^{2}
$$

where for $n$ trials, $F_{k}(f, t)$ is the spectral estimate of trial $k$ at frequency $f$ and time $t$. ERSP shows mean time-frequency points across the input epochs, where higher or lower spectral power differs from mean power during standing still $(4000 \mathrm{~ms}$ until $2000 \mathrm{~ms}$ before movement onset) for gait initiation and from four step cycles in the transition phase (HS1 until $2000 \mathrm{~ms}$ after HS1) for steps two, three, and four. To align time points between auditory beep and HS1 across participants, single trial spectrograms were computed for each participant and channel, and subsequently time-warped to the individual mean time interval between auditory beep and HS1 using the linear interpolation function available in the EEGLAB toolbox. For steps two, three and four, a similar method was used to time-warp single trial spectrograms to the individual mean time interval between HS1 and HS4. Finally, the grand average mean ERSP plots for $\mathrm{Cz}$ and $\mathrm{Fz}$ for all conditions were generated. To explore the possible influence of volume conduction, ERSP plots of electrodes neighbouring $\mathrm{Fz}$ and $\mathrm{Cz}$ were also generated, and presented in the Supplementary Material.

To provide additional insight regarding the spatial distribution of the most prominent phenomena found in the ERSP analysis at the $\mathrm{Cz}$ and Fz electrodes, 32channel ERSP scalp distribution maps were made for distinct time intervals around the auditory beep and movement onset, respectively.

\section{Statistical analysis}

SPSS version 23 for Windows (IBM Japan Ltd., Tokyo, Japan) was used for statistical analysis of participant and gait characteristics. To determine whether data distributions met the assumption of normality, histograms, Q-Q plots and measures of skewness and kurtosis were examined. For nonnormally distributed data, i.e., age, length, weight and MMSE, a Mann-Whitney $U$ test was used to compare between groups. Gender ratios between controls and PD were compared using Fisher's exact test. To compare normally distributed independent data, i.e., double support and swing phase duration of controls and both PD conditions, independent $t$-tests were used. To compare paired normally distributed values, i.e., double support and swing phase durations for PD starting naturally and with enhanced arm swing, paired $t$-tests were used. To test whether there is a difference in step length between the two PD conditions, a sign test was used.

MATLAB 2015a was used for comparing normalized and time-warped EMG envelopes of the four lower limb muscles between conditions. For comparison between controls and the two PD conditions, a Mann-Whitney U test was used. To compare EMG envelopes between naturally starting in PD and starting with enhanced arm swing, a Wilcoxon Signed Rank test was used. All $p$-values were corrected for multiple comparisons using the Benjamini-Hochberg false discovery rate $[90,91]$. To visualize eventrelated perturbations, significant differences from the baseline average gait cycle log spectrum were computed with a permutation method [89]. Significant ERSP differences between conditions were identified using a nonparametric permutation method corrected 
Table 1

Demographic characteristics of participants

\begin{tabular}{lccc}
\hline & HC $(\mathrm{N}=19)$ & PD $(\mathrm{N}=17)$ & $p$-value \\
\hline Age (years) & $67 \pm 12$ & $67 \pm 12$ & 0.452 \\
Sex ratio $(\mathrm{m} / \mathrm{f})$ & $9 / 10$ & $11 / 6$ & 0.335 \\
Length $(\mathrm{cm})$ & $178 \pm 19$ & $178 \pm 13$ & 0.778 \\
Weight $(\mathrm{kg})$ & $82 \pm 17$ & $77 \pm 13$ & 0.552 \\
MMSE score & $29 \pm 2$ & $29 \pm 2$ & 0.363 \\
Years since diagnosis & & $4.5 \pm 5.25$ & \\
LED $(\mathrm{mg})$ & & $750 \pm 639$ & \\
\hline
\end{tabular}

Values are expressed as median \pm interquartile range. Mann-Whitney $U$ tests were used for statistical testing, except for gender differences where a Fisher's exact test was used. MMSE, Mini-Mental State Exam; LED, Levodopa Equivalent Dose; HC, healthy controls; $\mathrm{PD}$, patients with Parkinson's disease.

for multiple comparisons using the false discovery rate method available within EEGLAB 14_1_2b. To compare between controls and the two PD conditions, unpaired statistics were used while for comparison between the two PD conditions paired statistics were used. For all statistical tests an alpha level of 0.05 was assumed.

\section{Data availability}

Obtained data are, on request, available from the corresponding author.

\section{RESULTS}

The PD patients and healthy control participants were matched for age, sex, length and body weight (see Table 1). PD patients had a median disease duration of $4.5 \pm 5.25$ years and were treated with a Levodopa equivalent dose of $750 \pm 639 \mathrm{mg}$ (median \pm interquartile range).

\section{Gait initiation; ERSP at $\mathrm{Fz}$ and $\mathrm{Cz}$}

In healthy control participants, a strong ERD in the alpha/beta band $(8-30 \mathrm{~Hz})$ emerged at the midline sites $\mathrm{Fz}$ and $\mathrm{Cz}$ (over the putative SMA and leg $\mathrm{M} 1$, respectively) in the second part of the interval between the starting cue and the actual onset of leg movement, as recorded by the ankle accelerometers, and continued during the subsequent swing phase of this leg (Fig. 1). In PD patients, this ERD was significantly reduced at $\mathrm{Fz}$, both before and after movement onset ( $p=0.019 ; p=0.016$, respectively), while at $\mathrm{Cz}$ such ERD reduction only reached statistical significance after movement onset $(p=0.032)$ (Fig. 1). Details on statistical significance concerning time intervals and frequency bands are provided in Supplementary Figure 1. In the PD condition with enhanced arm swing, the patient-related reduction in alpha/beta ERD significantly increased at Fz, both before $(p=0.004)$ and after movement onset $(p=0.003)$, thus virtually normalizing to controls. At $\mathrm{Cz}$, this increase of alpha/beta ERD only reached statistical significance after movement onset $(p=0.004)$. Moreover, the onset of the pre-movement beta ERD $(12-30 \mathrm{~Hz})$, recorded at both $\mathrm{Fz}$ and $\mathrm{Cz}$, occurred earlier when PD patients were instructed to start walking with enhanced arm swing, compared to either starting without such instruction or to healthy controls (Fig. 1). ERSP scalp maps additionally illustrate the characteristic alpha/beta ERD alterations over time for the three conditions at Fz (Fig. 2), of which particularly the PD-related changes around movement onset were also obvious in sensorimotor and lateral frontal areas. In order to provide background information illustrating that the effects at $\mathrm{Fz}$ are unlikely due to, e.g., volume conduction from particularly recording sites $\mathrm{C} 3$ and $\mathrm{C} 4$ at lateral motor regions, ERSP plots obtained from electrodes neighbouring $\mathrm{Fz}$ and $\mathrm{Cz}$ are presented in Supplementary Figure 2.

An intriguing observation was that around the time of the auditory cue, only in the PD patients a clear ERS in the theta/alpha $(4-12 \mathrm{~Hz})$ range occurred at both $\mathrm{Fz}$ and $\mathrm{Cz}$ when the patients had to start walking in a natural fashion, i.e., without additional arm swing (Fig. 1). This cue-related power change was neither seen in the control participants ( $\mathrm{Fz} p=0.005$; $\mathrm{Cz} p=0.004)$ nor in the PD patients after the instruction was given that the cue implied starting with enhanced arm swing ( $\mathrm{Fz} p=0.005 ; \mathrm{Cz} p=0.018)$ (see also the scalp maps, Fig. 2).

\section{Gait initiations; EMG activity and behavioural parameters}

When gait is started, the rectus femoris muscle of the leading limb is one of the first lower limb muscles 
A. Fz-Supplementary Motor Area

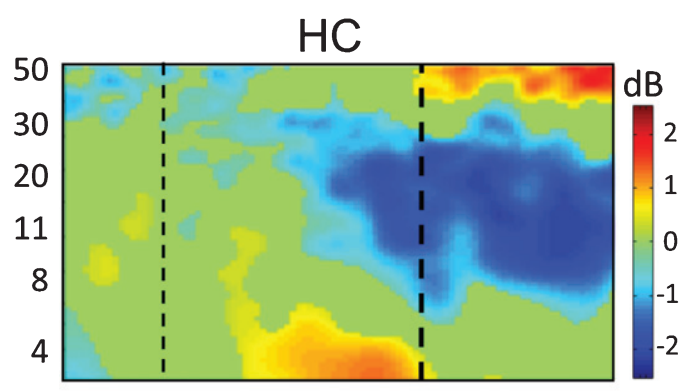

PD norm
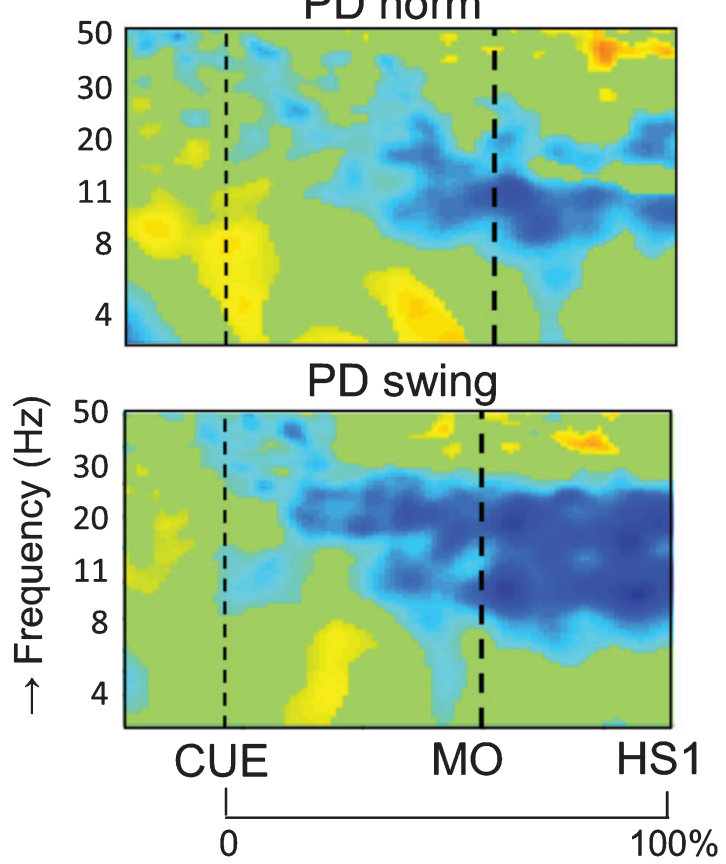

B.

$\mathrm{Cz}$ - Motor Cortex legs

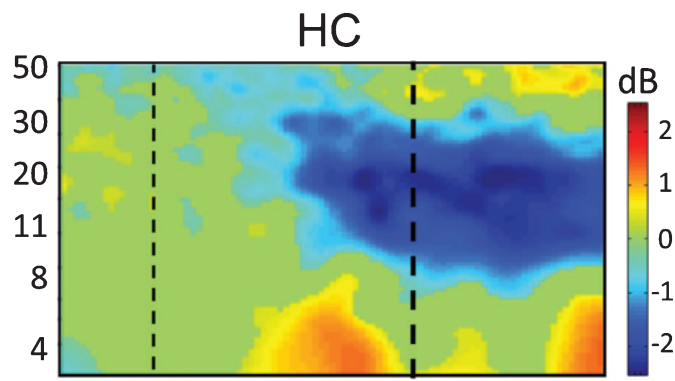

PD norm
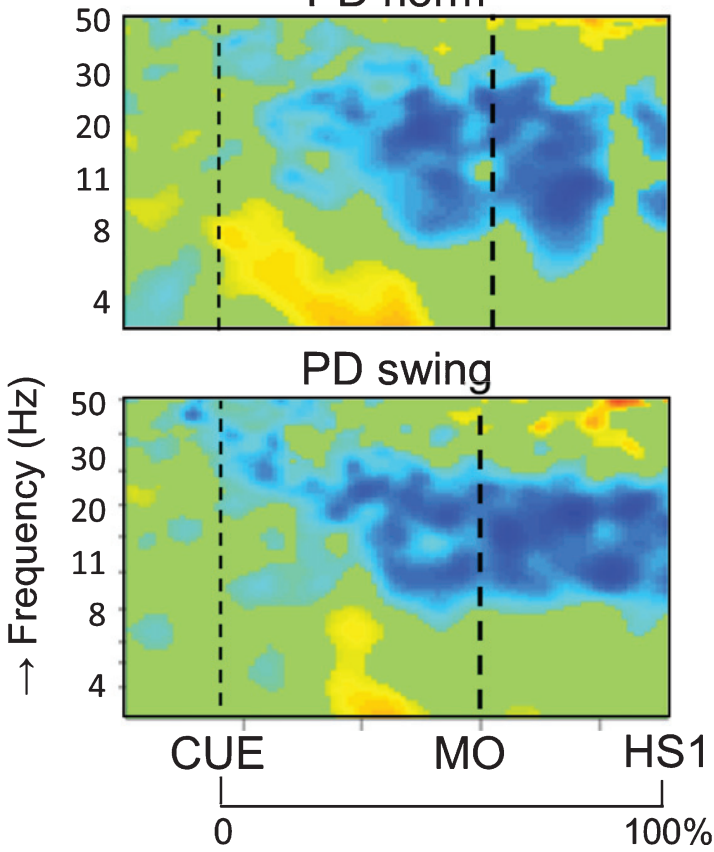

Fig. 1. ERSP plots of gait initiation. Group averaged dynamic changes across the EEG frequency spectrum from electrodes over the putative supplementary motor area (A) and the motor cortex of both legs (B) during gait initiation in healthy controls (HC), Parkinson patients starting according to normal baseline instruction (PD norm) and Parkinson patients starting with enhanced arm swing (PD swing). Event related desynchronization (ERD) is illustrated in blue and event related synchronization (ERS) in red. Vertical lines mark the occurrence of the beep (CUE), movement onset (MO) and first heel strike (HS1). Non-significant changes $(p>0.05)$ are set to $0 \mathrm{~dB}$ (green). ERSP, event related spectral perturbations; $\mathrm{dB}$, decibel

that becomes activated to initiate the swing phase. Natural gait initiation in PD, without additional instructions, revealed reduced EMG activity of this index muscle prior to movement onset compared to healthy controls $(p=0.017)$, while the interval between the auditory cue and movement onset was significantly prolonged ( $p=0.049)$ (Table 2, Fig. 3). Following the instruction to start walking with enhanced arm swing, rectus femoris EMG activity of the patients significantly increased $(p=0.019)$ and normalized to controls (Fig. 3). Moreover, movement onset became earlier, with a cue-movement interval which also normalized to that of the healthy control subjects (Table 2). The interval between the cue and forward bending, preceding movement onset, was also prolonged in the patients compared to healthy controls $(p=0.041)$ and became shorter following the instuction of enhanced arm swing. However, the ratio of the cue-bending interval relative to the cue-movement interval remained similar in the three conditions (around 0.66) (Table 2). Although the observed effects on muscle activity were most pronounced in the rectus femoris muscles of both leading and trailing limb, they were also observed 

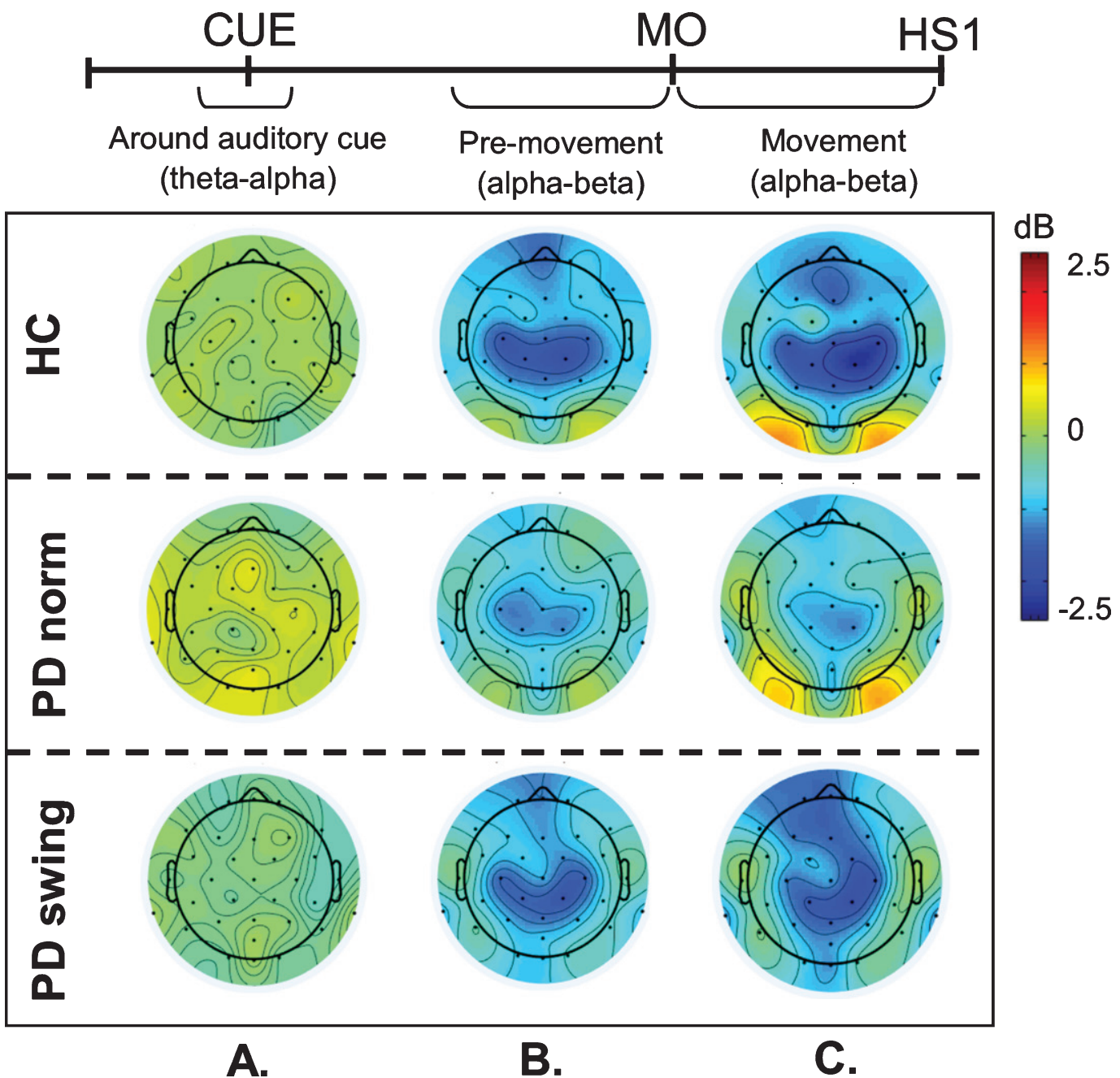

Fig. 2. ERSP scalp distribution maps during gait initiation. Group averaged topographic distribution of the event related spectral perturbations (ERPS) over the entire scalp (32 channels) during gait initiation in healthy controls (HC, upper row), normal baseline starting in Parkinson patients (PD norm, middle row) and Parkinson patients starting with enhanced arm swing (PD swing, lower row). Regarding the multiple stages of gait initiation, the three most prominent time-intervals, characterized by distinct frequency bands recorded at Fz and $\mathrm{Cz}$ electrode were selected, i.e., the interval between $100 \mathrm{~ms}$ prior and $100 \mathrm{~ms}$ after the auditory cue (CUE), the $500 \mathrm{~ms}$ interval preceding movement onset (MO) and the interval between MO and first heel strike (HS1). Event related desynchronization (ERD) is illustrated in blue, event related synchronization (ERS) in red. $\mathrm{dB}$, decibel

during movement onset in the tibialis anterior, soleus and biceps femoris muscles of the leading limb (Fig. 4). During the first step following movement onset, rectus femoris EMG activity of PD patients in the baseline condition remained reduced, particularly around heel strike $(p=0.018)$. With enhanced arm swing, this reduced agonistic EMG activity significantly increased around both toe off $(p=0.019)$ and heel strike ( $p=0.003)$ (Fig. 3).

EMG activity of the upper-limb deltoideus muscle showed small differences between baseline PD and healthy controls: 1) anterior deltoideus activ- ity was slightly lower after movement onset, but only reached a significant difference around the first heel strike $(p=0.039)$, while 2$)$ posterior deltoideus activity in baseline PD was significantly lower both around movement onset $(p=0.033)$ and first heelstrike ( $p=0.018)$ (Fig. 5). The instruction of enhanced arm swing in PD indeed resulted in a significant increase of deltoideus EMG activity after movement onset, with an alternating activity pattern for the anterior and posterior muscle groups (Fig. 5). Now, EMG activity in PD exceeded that in healthy controls, which was most pronounced in the anterior 
Table 2

Spatiotemporal gait characteristics based on accelerometer data and video recordings

\begin{tabular}{|c|c|c|c|c|}
\hline & $\mathrm{HC}$ & PD norm & PD swing & \\
\hline \multicolumn{5}{|l|}{ A) Duration (ms) } \\
\hline \multicolumn{5}{|l|}{ 1) Double support phase } \\
\hline CUE-MO interval & $928 \pm 115^{\mathrm{a}}$ & $1015 \pm 136$ & $961 \pm 118$ & \\
\hline CUE-BEND interval & $606 \pm 72^{\mathrm{a}}$ & $684 \pm 101$ & $650 \pm 110$ & \\
\hline CUE-BEND/CUE-MO & $0.65 \pm 0.03$ & $0.67 \pm 0.03$ & $0.67 \pm 0.03$ & \\
\hline Step 1 & $174 \pm 46^{\mathrm{ab}}$ & $249 \pm 64$ & $215 \pm 61$ & \\
\hline Step 2 & $165 \pm 38^{\mathrm{a}}$ & $205 \pm 73$ & $194 \pm 81$ & \\
\hline Step 3 & $162 \pm 41^{\mathrm{ab}}$ & $203 \pm 69$ & $202 \pm 70$ & \\
\hline \multicolumn{5}{|l|}{ 2) Swing phase } \\
\hline Step 1 & $685 \pm 147$ & $656 \pm 154$ & $609 \pm 202$ & \\
\hline Step 2 & $466 \pm 72^{\mathrm{a}}$ & $388 \pm 91$ & $437 \pm 198$ & \\
\hline Step 3 & $450 \pm 79^{\mathrm{ab}}$ & $369 \pm 117$ & $373 \pm 109$ & \\
\hline Step 4 & $442 \pm 67^{\mathrm{ab}}$ & $439 \pm 94$ & $347 \pm 119$ & \\
\hline B) Relative step length & & & & PD swing/norm \\
\hline Step 1 & & & & $1.17 \pm 0.37^{\mathrm{c}}$ \\
\hline Step 2 & & & & $1.12 \pm 0.22^{\mathrm{d}}$ \\
\hline Step 3 & & & & $1.15 \pm 0.22^{\mathrm{d}}$ \\
\hline Step 4 & & & & $1.02 \pm 0.16$ \\
\hline
\end{tabular}

The swing phase is the interval between toe-off and heel strike, while the double support phase is the interval between heel strike and toe-off of the opposite leg. The interval measurements are obtained by accelerometer recordings. PD swing/norm is the step length ratio of the two conditions, based on the video recordings. Values are expressed as mean \pm standard deviation, except for the relative step length which is expressed as median \pm interquartile range. ${ }^{\mathrm{a}}$ difference with PD norm, independent $t$-test. $p<0.05 ;{ }^{\mathrm{b}}$ difference with PD swing, independent $t$-test. $p<0.05 ;{ }^{\mathrm{c}}$ difference $p<0.001$, sign-test; ${ }^{\mathrm{d}}$ difference $p<0.05$, sign-test. CUE, auditory beep; MO, movement onset; BEND, forward bending; CUE-BEND/CUE-MO, ratio of the two indicated intervals, no significant differences; $\mathrm{HC}$, healthy controls; PD norm, Parkinson patients starting according to normal baseline instructions; PD swing, Parkinson patients starting with enhanced arm swing.

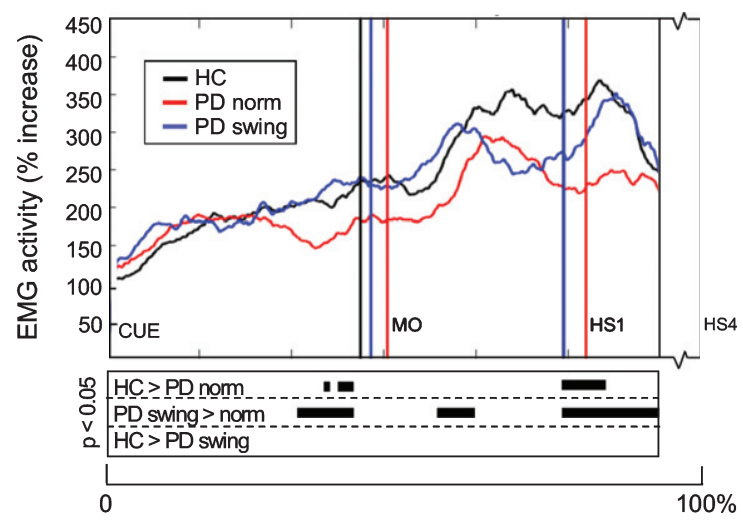

Fig. 3. Rectus Femoris EMG activity of the leading limb during gait initiation. Group averages of EMG activity, which are timenormalized for the interval between the beep (CUE) and fourth heel strike (HS4), are presented for the Rectus Femoris of the leading limb. The muscle activity is displayed as percentage increase relative to the activity when standing still, given for the healthy controls (HC, black), Parkinson patients starting according to normal baseline instruction (PD norm, red) and Parkinson patients starting with enhanced arm swing (PD swing, blue). Vertical lines mark the mean group latencies of movement onset (MO) and first heel strike (HS1). Beneath the activity curves, black squares display the time points with significant differences between conditions (corrected $p<0.05$, Mann-Whitney $\mathrm{U}$ for independent data and Wilcoxon Signed Rank for paired data). deltoideus. Before movement onset, increase of EMG activity occurred in both deltoideus muscle groups, which was most pronounced in the anterior deltoideus $(p=0.001)$. Although enhanced arm swing had no effect on the duration of the leg's first swing phase in PD patients, the first step was made over a significantly larger distance $(p<0.001)$ (Table $2 \mathrm{~B})$, which indicates that enhanced arm swing increases the step velocity in PD.

\section{First gait cycles; EMG and behavioural parameters}

During steps two, three and four, representing the transition to regular gait, the reduced agonist EMG activity of the lower limbs persisted in baseline gait of the PD patients (Fig. 4). This agonistic activity normalized towards that of healthy controls when PD patients started walking with enhanced arm swing, which was particularly seen during the first three steps. These findings were most pronounced during the double support phase prior to toe off, in the tibialis anterior, soleus and biceps femoris muscles of leading and trailing limb. Significant reduction of rectus 
A. Tibialis Anterior - leading limb

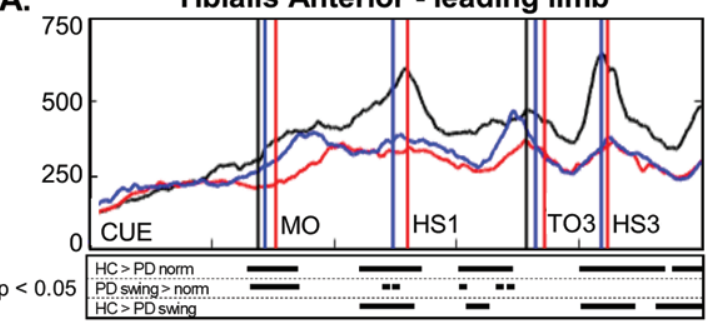

C.

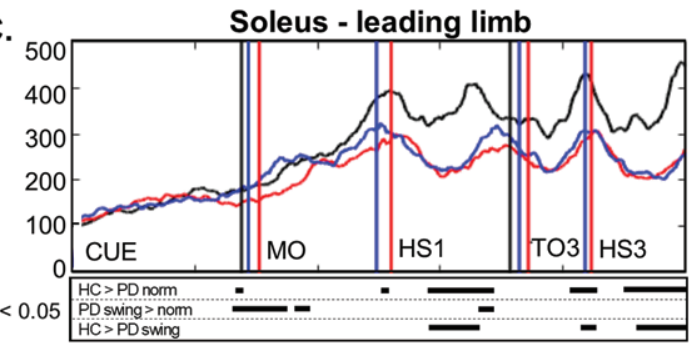

E.
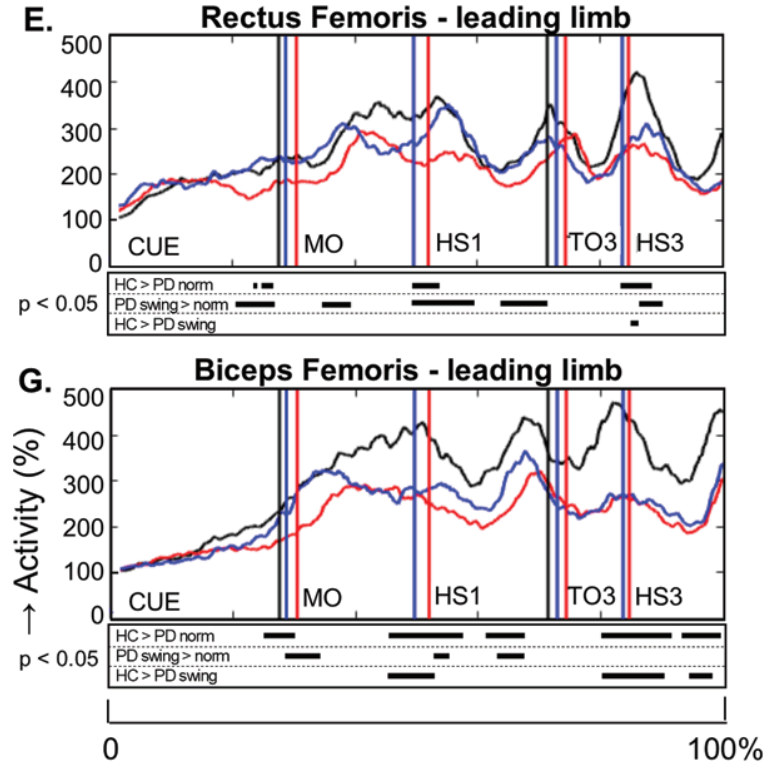

B.

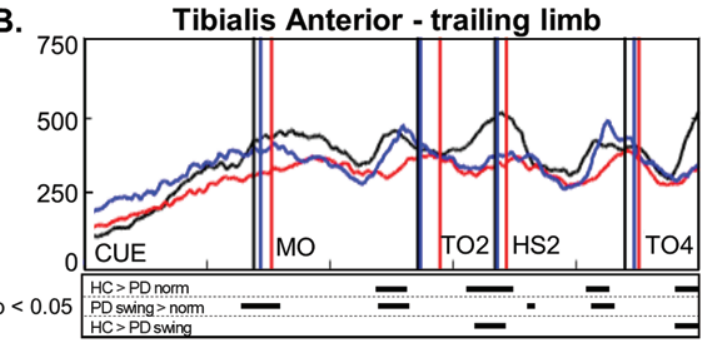

D.
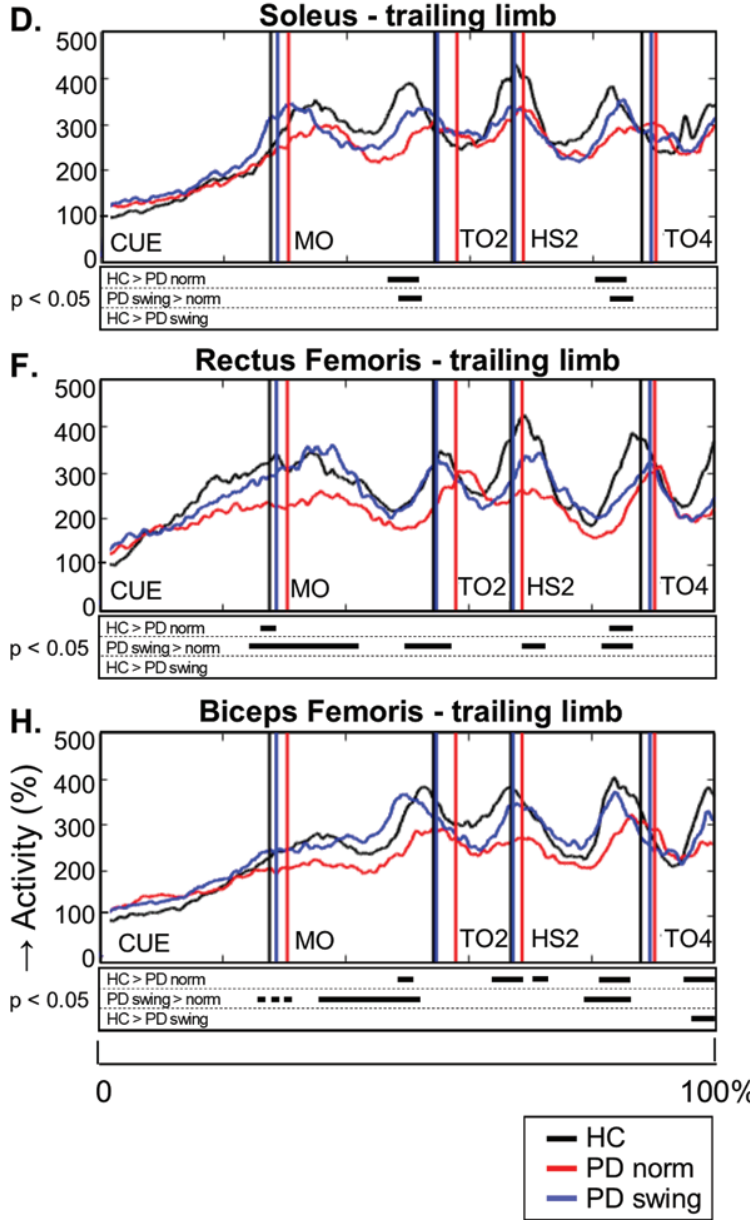

Fig. 4. Lower limb EMG activity during gait initiation and three subsequent steps. Time-normalized group averages of the electromyography (EMG) activity of four lower limb muscles of the leading limb (A, C, E, G) and trailing limb (B, D, F, H) from the moment of the auditory cue until fourth heel strike measured in healthy controls (HC, black), Parkinson patients starting according normal baseline instruction (PD norm, red) and Parkinson patients starting with enhanced arm swing (PD swing, blue). Muscle activity is displayed as percentage increase relative to mean muscle activity when standing still. Vertical lines mark mean group latencies of movement onset (MO), first until fourth heel strike (HS4) and first until fourth toe-off (TO) relative to the auditory cue. Black squares beneath the EMG activity plots show time points with significant differences between conditions (corrected $p<0.05$, Mann-Whitney $\mathrm{U}$ for independent data and Wilcoxon Signed Rank for paired data).

femoris activity in baseline gait of the PD patients, when compared to controls, mainly occurred around heel strike (step one, two, three). Rectus femoris activity increased with enhanced arm swing gait both around heel strikes and in the double support phase prior to toe off. Baseline PD gait was further characterized by a prolonged double support phase in the first three steps $(p<0.001 ; p=0.049 ; p=0.044)$ in combination with a shorter swing phase of step two $(p=0.008)$, three $(p=0.021)$, and four $(p=0.002)$ 
Deltoideus Anterior

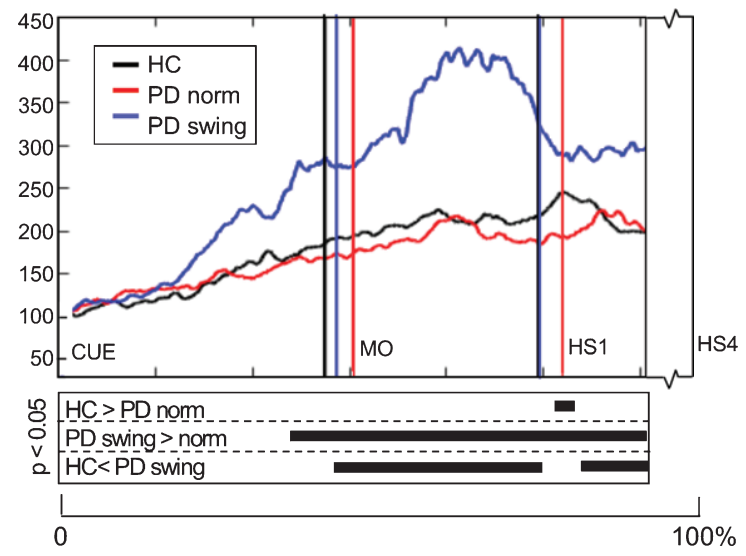

Deltoideus Posterior

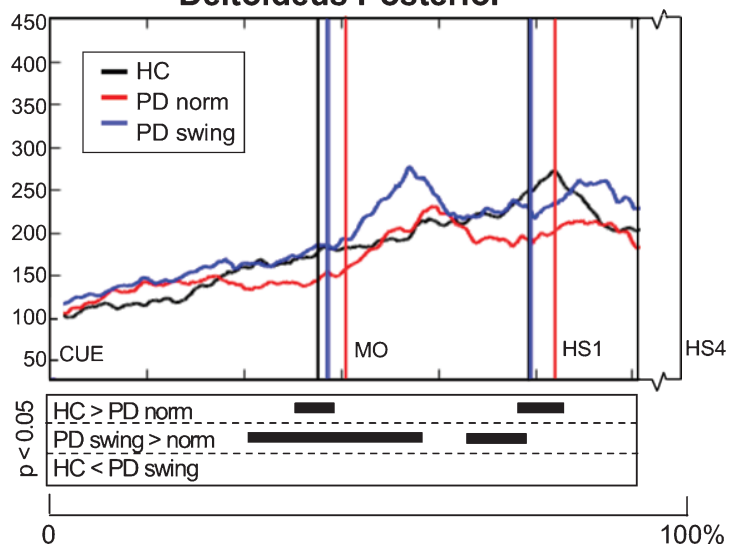

Fig. 5. Deltoideus EMG activity of the leading arm during gait initiation. Group averaged EMG activity, time-normalized for the interval between the beep (CUE) and fourth heel strike (HS4), of anterior and posterior deltoid muscle of the leading arm, measured in healthy controls (HC, black), Parkinson patients starting according normal baseline instruction (PD norm, red) and Parkinson patients starting with enhanced arm swing (PD swing, blue). Muscle activity is displayed as percentage increase relative to muscle activity when standing still. Vertical lines mark mean group latencies of movement onset (MO) and first heel strike (HS1). The significance plots underneath the activity plots display black squares at time points with significant differences between conditions (corrected $p<0.05$, Mann-Whitney $\mathrm{U}$ for independent data and Wilcoxon Signed Rank for paired data).

compared to controls (Table 2A). This might be a result of reduced step velocity and a shorter step length, respectively. Only in the second step, walking with enhanced arm swing in PD patients resulted in a normalization of these alterations towards controls. Step length, however, increased during the first three steps (Table 2B, $p<0.001 ; p=0.001$; $p=0.020$, respectively), indicating an increased step velocity in PD when walking with enhanced arm swing.
First gait cycles; ERSP at $\mathrm{Fz}$ and $\mathrm{Cz}$

ERSP at $\mathrm{Fz}$ and $\mathrm{Cz}$ during steps two, three and four revealed a general step-related pattern of ERD-ERS alternation in both the healthy control and the two PD walking conditions (Fig. 6). The phase of the pattern slightly differed for various frequency bands. At Fz, ERD in the high-beta/low gamma bands (20-40 $\mathrm{Hz}$ ) was prominent in all three conditions during the double support phase, i.e., in the phase between heel strike and lifting the toe of the other leg from the floor, while it extended into the swing phase of particularly the healthy participants. During double support, this ERD at Fz was reduced in baseline PD gait, compared to healthy controls $(p=0.027)$, while it significantly increased in PD with enhanced arm swing, compared to baseline PD gait $(p=0.006)$. Details on statistical significance are provided in Supplementary Figure 3. At the end of the swing phase, ERS was seen in the high-beta/low gamma bands in healthy controls and the two PD conditions, both at Fz and Cz. As the steps two, three and four represent a transition between gait initiation and stable gate, which was not the primary scope of the present study, we refrained from extensive ERSP descriptions for all possible frequency bands. However, the above described EMG and kinematical analysis of the transition data was particularly informative because it provided information about persistence of the improved onset of PD gait with enhanced arm swing during this initial walking stage.

\section{DISCUSSION}

The simultaneous acquisition of ambulatory EEG, EMG, accelerometer, and audio-video recordings provided data for optimal analysis of the temporal relationships between cerebral and muscle activities and actual movement onset during gait initiation. In this way, we were able to demonstrate differences between healthy subjects and PD patients, while the beneficial effect of enhanced arm swing added to the obtained insight in cerebral mechanisms underlying impaired gait initiation in PD. The latter was associated with reduced preparatory and movementrelated ERD as well as reduced agonist lower limb muscle activity at these two stages. Both ERD and EMG activity virtually normalized to that of healthy controls when the patients started walking with the instruction of enhanced arm swing, while movement onset became earlier. Moreover, increased ERS occurred at the moment of the auditory starting cue 


\section{A. Fz - Supplementary Motor Area}
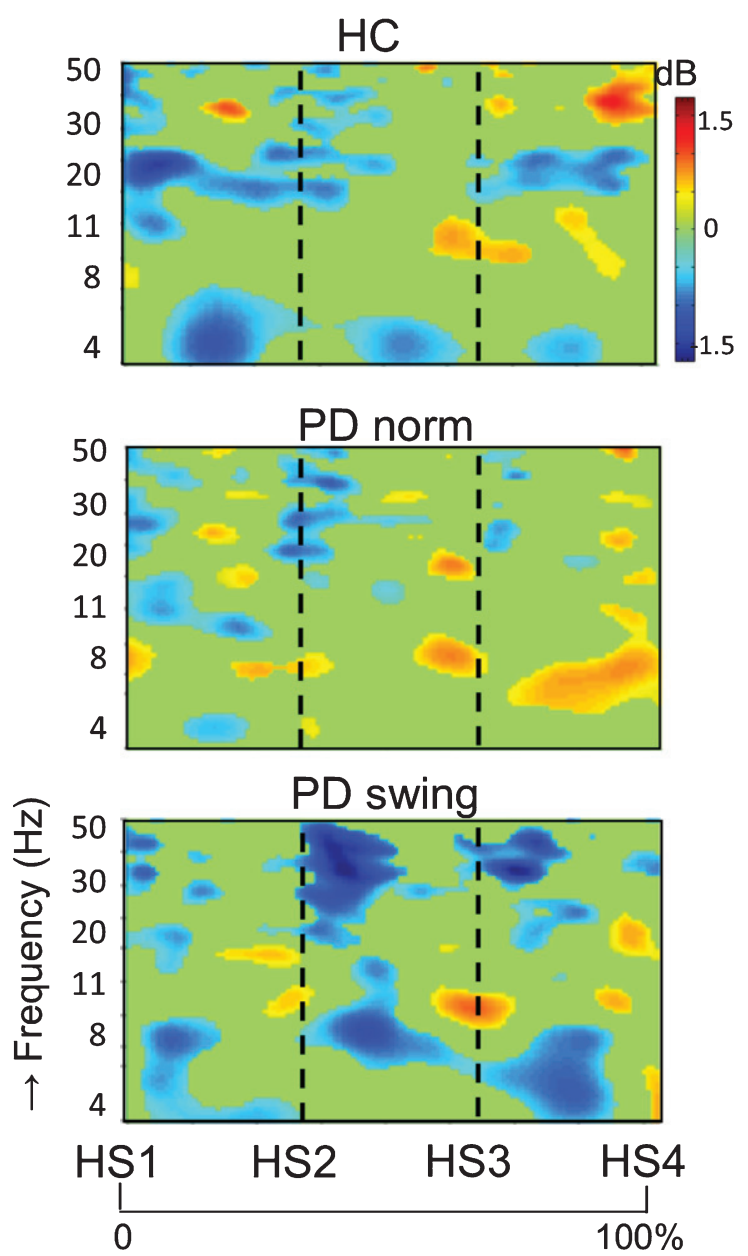

B.

Cz - Motor Cortex (legs)
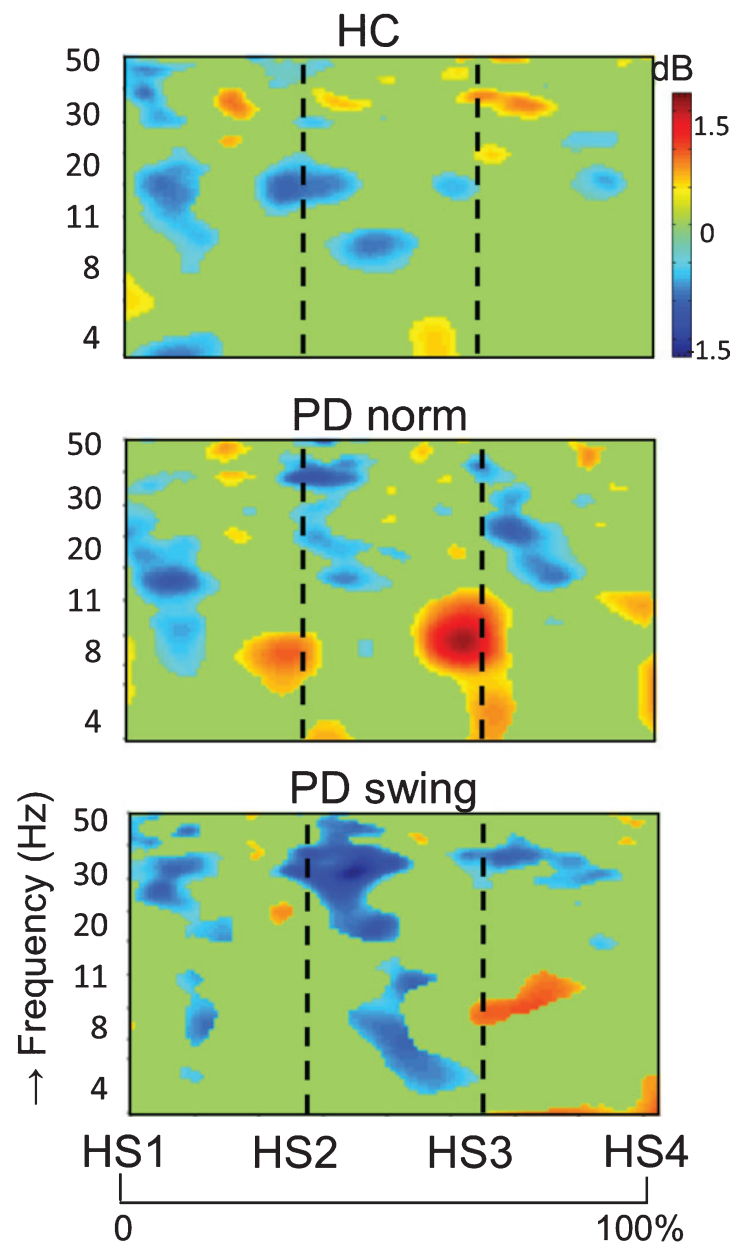

Fig. 6. ERSP plots during step two, three and four. Dynamic changes across the EEG frequency spectrum from electrodes over the putative supplementary motor area and the motor cortex of the legs during the transition steps two, three and four towards regular gait, in healthy controls (HC, upper row), Parkinson patients starting according normal baseline instruction (PD norm, middle row) and Parkinson patients starting with enhanced arm swing (PD swing, lower row). Event related desynchronization (ERD) is illustrated in blue and event related synchronization (ERS) in red. ERSP, event related spectral perturbations; HS1, first heel strike; HS2, second heel strike; HS3, third heel strike; HS4, fourth heel strike; dB, decibel.

only in the PD baseline condition, while this altered electrocortical activity disappeared when PD patients had to start with enhanced arm swing. The characteristic alterations in electrocortical activity were recorded at $\mathrm{Fz}$ and $\mathrm{Cz}$, representing the putative SMA and leg area of M1, respectively. We indeed acknowledge that the effects at particularly Fz may arise from a more extended medial frontal region, constituted by a mixture of underlying sources. This is further treated at the end of the discussion.

The inference that ERD power may generally reflect cerebral activity associated with movement preparation is a well-accepted concept [38-40].
Moreover, such activity has also been associated with steady state walking, compared to standing $[35,36$, $58]$ as well as gait adaptation compared to steady state walking [67, 92]. Particularly the preparation-related activity supports our conclusion that the observed reduction of alpha/beta ERD power over the putative SMA of PD patients when preparing baseline gait initiation, together with reduced lower-limb agonist muscle activity in the pre-movement phase, indeed represents impaired preparation of gait, causing the delayed movement onset in these patients. It would thus highlight the involvement of a reduced SMA function in difficulties of gait initiation. In PD, a 
characteristic feature of cerebral electrophysiology is the abrupt appearance of increased beta frequency oscillations $(13-30 \mathrm{~Hz})$, both measured in the basal ganglia and in the EEG [41, 71, 93, 94]. One might consider that such synchronized activity has a potential counter effect on ERD that contributed to the reduced ERD power demonstrated in our patients.

The gain in ERD power over particularly the putative SMA of the PD patients when following the instruction to start walking with enhanced arm swing, associated with increased agonistic muscle activity and earlier onset of actual walking, indicates a functional restoration of this cortical region. In this respect, the attentive use of enhanced arm swing appears to have a therapeutic effect. A similar relation between therapy and either a reduction of aberrant beta oscillations or an increased ERD power has been demonstrated for both dopaminergic medication and deep brain stimulation [24, 44, 45, 71, 93-97].

The experimental condition in which PD patients had to start with enhanced arm swing implied that the auditory cue, which remained identical to the cue in the baseline condition, was now labelled with a new specific meaning. A remarkable observation, in this respect, was the theta/alpha ERS that occurred over the putative SMA around the time of the auditory cue in only baseline PD gait initiation. This might be consistent with similar ERS over the SMA, as well as occipital regions, that has been reported in the transition towards PD freezing of gait [98, 99]. This has been suggested to express difficulty in dealing with conflict related signals $[100,101]$. As PD patients with gait initiation difficulties seem to overrely on visual information to compensate for a loss of or altered kinaesthetic feedback [98, 102], enhanced vulnerability for external cues may easily induce a block of responses in case of multiple (non-aligned) cues. This points at a similarity with enhanced dualtask interference in PD [103]. Effective cues are assumed to assist in prioritization during response selection under conflict, e.g., by reducing the interference of salient environmental input and redirect the focus of attention towards gait [104, 105]. In our design, one may assume that the starting cue with minimal contextual information in the baseline condition, demands an internal search for context with an increased risk of conflict between potential motor options. As more context is provided in PD on how to start walking, using the instruction for enhanced arm swing, the risk of blocks due to (internal) response conflict is reduced, which was indeed associated with disappearance of the theta/alpha ERS. In other words, in the condition with enhanced arm swing, the simple auditory beep becomes a more informative semiinternal cue that assists in this prioritization. The fact that the theta/alpha ERS already emerges around the cue may point at a component of anticipation on the cue information.

Such 'anticipation' on the additional meaning of the cue (enhanced arm swing), and not just anticipating the auditory signal, is consistent with the model that expectations are more critical for kinetic improvement in PD than the actual sensory cue [106]. Additional context knowledge of the beep might thus serve as a semi-internal cue, enhancing attention towards gait initiation with recruitment of a stored motor program, equivalent to the effect of external cues [11-14]. Such 'internally' cued motor recruitment is strikingly expressed by the responses of a former football player with $\mathrm{PD}$, suffering from severe freezing of gait, who runs fluently when given a football [107]. Higher-order 'internal' cuing also fits the effect of verbal instructions to improve gait or gait initiation by, e.g., imagining bicycling, which has been shown to alleviate freezing of gait in PD patients [108]. Similarly, verbal instructions to increase step length enable normalization of gait parameters in PD [46, 109]. These strategies have been regarded to employ instructional sets and deliberate attention to specific elements of 'normal' walking that may bypass basal ganglia circuitry and activate prefrontal and premotor areas to prepare the motor cortex for locomotion [109, 110]. Consistent with such mechanism, Nonnekes and co-workers proposed that compensation strategies for freezing of gait might involve the introduction of more goal directedness, with use of motor programs that are less overlearned [111]. It might be noticed, in this respect, that the instruction to start walking with enhanced arm swing was given only once, at the beginning of the series of 30 starting trials. This implies that the instruction of enhanced arm swing was covertly repeated, indicating that the auditory signal recruited a 'mental image' of starting with enhanced arm swing, which underscores the inference of a semi-internal cue.

A second mechanism to consider is that anticipating enhanced arm swing, independent from gait, might be associated with enhanced SMA activity during the preparation phase, which would more easily co-activate the legs cyclic movements. In this respect, neural interactions at spinal cord and brain levels underlying coupling of four-limb muscle activities during gait [112-114] might facilitate an extra preparatory boost to lower limb activity by enhanced 
arm swing. The observed arm swing-related increase of lower-limb muscle activity in PD during the preparation of gait initiation provides an argument for such early brain - spinal cord interactions. At this level of interactions, one may also consider that anticipating gait initiation with enhanced arm swing might contribute to a forward shift of the center of gravity in the PD patients, which would imply improved anticipatory postural adjustment [115-117]. We did indeed observe that forward bending followed the cue faster when patients were instructed to start with enhanced arm swing, but the fact that the ratio between this interval and the time between the cue and actual movement onset remained similar indicates that improved anticipatory postural adjustment was not an independent factor to explain this improvement.

In the transition phase between the onset of movement and steady state gait, the alternating ERD-ERS pattern we found in healthy participants is in agreement with the pattern described in previous studies $[35,58,59,67,118,119]$. A difference with healthy participants was that in the PD baseline condition, a reduced beta and low gamma ERD was present over the putative SMA of the patients, similar to the ERD reduction during gait preparation. This PDrelated reduction of ERD in the alternating ERD-ERS pattern over this medial frontal region is consistent with a reduced contribution of this region to efficient four-limb movements [31]. A consequence of such functional impairment of the putative SMA may be that the leg M1 is challenged to make an enhanced effort to organize the legs cyclic movement pattern [31,35]. The latter was indeed indicated by the stronger high frequency ERD observed over M1 in the present study. The theta/alpha ERS in PD patients at the end of the swing phase may similarly be seen as an indicator of reduced gait efficiency, as it has been proposed to represent a control strategy for postural stability during more complex walking tasks in healthy participants [120-122]. The reduced lower limb muscle activity and observed parameters for reduced step length and velocity found in our PD patients underscore such relation with reduced efficiency [56]. As the aim of the present study was to assess gait initiation, the established persistence of the beneficial effect of enhanced arm swing during the transition phase, revealed by improved muscle activity of the lower limb muscles, increased step length and velocity, adds to its value in gait initiation. Also at cortical level, the increase of ERD power over the putative SMA in PD patients with enhanced arm swing provides support for its lasting effect immediately after gait initiation.

As stated in the first paragraph of the Discussion, the characteristic alterations in electrocortical activity that were recorded at $\mathrm{Fz}$ and $\mathrm{Cz}$ were inferred to represent activity in the putative SMA and leg area of M1, respectively. We thus acknowledge that the SMA and M1 cannot be used as synonyms for the EEG channels. Moreover, recordings from EEG channels in movement studies are prone to artefact contamination [84, 87, 88]. To address these issues, the following methodological considerations are further elaborated. Recently, several artefact rejection methods, such as ICA in combination with dipole analysis, have been applied to study oscillatory activity during walking [35, 84]. Due to the limited number of 32 electrodes in the present study, ICA was restricted in extracting specifically movement artefacts. On the other hand, it should be noted that similarity between our data and prior results indicates that cautious data pre-processing and critical evaluation of EEG phasic changes yielded comparable data quality (see also [31]). This is further supported by the observation that intra-cycle power modulations occurred in a physiologically limited frequency band and not as broadband activity. The latter would be expected in case of motion-induced artefact contamination [87] and particularly muscular artefacts due to activity of the neck muscles [84]. In this respect, it should be recognized that the core findings of our study concerned ERSP during the preparation of gait initiation, i.e., without overt movement.

When interpreting condition-related differences in cortical activity, one needs to keep in mind that $\mathrm{Fz}$ and $\mathrm{Cz}$ are located in near vicinity of each other on the scalp, which implies that, while located above the putative SMA and leg area of M1, the recorded activity may result from a mixture of underlying sources. For this reason, one cannot unequivocally assign the observed effects to a distinct single brain region such as the SMA. One might even oppose that, due to volume conduction, the observed effects at Fz may be attributed to bilateral arm representations of M1. Arguments against this option are that, particularly in the pre-movement phase, effects are stronger at $\mathrm{Fz}$ than at $\mathrm{Cz}$. Moreover, also after movement onset, effects at the recording sites $\mathrm{FC} 1$ and FC2 were smaller than the effects found at both $\mathrm{Fz}$ and the lateral $\mathrm{M} 1$ sites $\mathrm{C} 3$ and $\mathrm{C} 4$, while $\mathrm{FC} 1$ and $\mathrm{FC} 2$ are positioned in-between $\mathrm{Fz}-\mathrm{C} 3$ and $\mathrm{Fz}-\mathrm{C} 4$, respectively. Finally, the scalp maps showed that especially the ERS found at the moment of auditory beep was 
specifically derived from $\mathrm{Fz}$, and was not present at $\mathrm{Cz}, \mathrm{C} 3$ or $\mathrm{C} 4$. For these reasons we regard it plausible that the effects at $\mathrm{Fz}$ and $\mathrm{Cz}$ can be related to a medial frontal region that includes the SMA. Future studies with more EEG channels, enabling a higher spatial resolution are necessary to further identify contributions of the SMA, pre-SMA and/or cingulate motor cortex to the observed effects.

In conclusion, gait initiation of PD patients improved when they were instructed to start with enhanced arm swing. This improvement was associated with normalization of EEG, EMG and kinematic parameters. The disappearance of excessive ERS over the putative SMA, that was seen around the auditory cue in baseline PD starting, might indicate that the cue's contextual information of enhanced arm swing reduced potential response conflict, which is enhanced in PD, with the consequence that the auditory signal now served as a semi-internal cue facilitating recruitment of a stored motor program. Gain of ERD power over the putative SMA of PD patients during the second part of the preparation stage before the actual onset of movement, together with normalization of reduced muscle activity, further underscored the improved efficiency of preparing gait initiation. Particularly the increase of agonist lower limb muscle activity when preparing gait initiation with enhanced arm swing indicates that preparing arm swing may co-activate the intended cyclic movements of the legs, mediated by a higher level of SMA activation.

\section{ACKNOWLEDGMENTS}

We would like to thank the patients, their partners and the healthy participants who participated in this study.

J.W. was supported by a MD/PhD grant from the Junior Scientific Masterclass of the University of Groningen.

\section{CONFLICT OF INTERESTS}

The authors report no conflict of interests

\section{SUPPLEMENTARY MATERIAL}

The supplementary material is available in the electronic version of this article: https://dx.doi.org/ 10.3233/JPD-202112.

\section{REFERENCES}

[1] Kalia LV, Lang AE (2015) Parkinson's disease. Lancet 24, 92-98.

[2] Postuma RB, Berg D, Stern M, Poewe W, Marek K, Litvan I, Lang AE, Halliday G, Christopher G, Gasser T, Dubois B, Chan P, Bloem BR, Adler CH, Deuschi G (2015) MDS clinical diagnostic criteria for Parkinson's disease. Mov Disord 30, 1591-1599.

[3] Hu F, Gu DY, Chen JL, Wu Y, An BC, Dai KR (2012) Contribution of arm swing to dynamic stability based on the nonlinear time series analysis method. Conf Proc IEEE Eng Med Biol Soc 2012, 4831-4834.

[4] Huang X, Mahoney J, Lewis M, Du G, Piazza S, Cusumano J (2013) Both coordination and symmetry of arm swing are reduced in Parkinson's disease. Gait Posture 35, 373-377.

[5] Lewek MD, Poole R, Johnson J, Halawa O, Huang X (2010) Arm swing magnitude and asymmetry during gait in the early stages of Parkinson's disease. Gait Posture 31, 256-260.

[6] Giladi N, Treves TA, Simon ES, Shabtai H, Orlov Y, Kandinov B, Paleacu D, Korczyn AD (2001) Freezing of gait in patients with advanced Parkinson's disease. $J$ Neural Transm 108, 53-61.

[7] Giladi N, McMahon D, Przedborski S, Flaster E, Guillory S, Kostic V, Fahn S (1992) Motor blocks in Parkinson's disease. Neurology 42, 333-9.

[8] Cowie D, Limousin P, Peters A, Day BL (2010) Neuropsychologia insights into the neural control of locomotion from walking through doorways in Parkinson's disease. Neuropsychologia 48, 2750-2757.

[9] van der Hoorn A, Hof AL, Leenders KL, de Jong BM (2012) Narrowing wide-field optic flow affects treadmill gait in left-sided Parkinson's disease. Mov Disord 27, $580-581$.

[10] Okuma Y (2006) Freezing of gait in Parkinson's disease. J Neurol 253, 27-32.

[11] Nieuwboer A (2008) Cueing for freezing of gait in patients with Parkinson's disease: A rehabilitation perspective. Mov Disord 23, 475-481.

[12] Schubert M, Prokop T, Brocke F, Berger W (2005) Visual kinesthesia and locomotion in Parkinson's disease. Mov Disord 20, 141-150.

[13] Snijders AH, Weerdesteyn V, Hagen YJ, Duysens J, Giladi N, Bloem BR (2010) Obstacle avoidance to elicit freezing of gait during treadmill walking. Mov Disord 25, $57-63$.

[14] Suteerawattananon M, Morris GS, Etnyre BR, Jankovic J, Protas EJ (2004) Effects of visual and auditory cues on gait in individuals with Parkinson's disease. J Neurol Sci 219, 63-69.

[15] Hallet M (2008) The intrinsic and extrinsic aspects of freezing of gait. Mov Disord 23, 439-443.

[16] Hanakawa T, Fukuyama H, Katsumi Y, Honda M (1999) Enhanced lateral premotor activity during paradoxical gait in Parkinson's disease. Ann Neurol 45, 329-336.

[17] Praamstra P, Stegeman DF, Cools AR, Horstink MWIM (1998) Reliance on external cues for movement initiation in Parkinson's disease Evidence from movement-related potentials. Brain 121, 167-177.

[18] Brass M, Haggard P (2008) The what, when, whether model of intentional action. Neuroscientist 14, 319-325.

[19] Lau HC, Lau HC, Rogers RD, Haggard P, Passingham RE (2004) Attention to Intention. Science 303, 1208-1210. 
[20] Rushworth MFS (2008) Intention, choice, and the medial frontal cortex. Ann N Y Acad Sci 1124, 181-207.

[21] Dirnberger G, Frith CD, Jahanshahi M (2005) Executive dysfunction in Parkinson's disease is associated with altered pallidal - frontal processing. Neuroimage 25, 588-599.

[22] Eimeren T Van, Monchi O, Ballanger B, Strafella AP (2010) Dysfunction of the default mode network in Parkinson disease: A functional magnetic resonance imaging study. Arch Neurol 66, 877-883.

[23] van der Hoorn A, Renken RJ, Leenders KL, de Jong BM (2014) Parkinson-related changes of activation in visuomotor brain regions during perceived forward self-motion. PLoS One 9, e95861.

[24] Jahanshahi M, Jenkins H, Brown RG, Marsden CD, Passingham RE, Brooks DJ (1995) Self-initiated versus externally triggered movements I. An investigation using measurement of regional cerebral blood flow with PET and movement-related potentials in normal and Parkinson's disease subjects. Brain 118 (Pt 4), 913-933.

[25] Jenkins IH, Fernandez SW, Playford ED, Lees AJ (1992) Impaired activation of the supplementary motor area in Parkinson's disease is reversed when akinesia is treated with apomorphine. Ann Neurol 32, 749-757.

[26] Brinkman C (1984) Supplementary motor area of the monkey's cerebral cortex: Short- and longterm deficits after unilateral ablation and the effects of subsequent callosal section. J Neurosci 4, 918-929.

[27] Debaere F, Swinnen SP, Be E, Sunaert S, Hecke P Van, Duysens J (2001) Brain areas involved in interlimb coordination: A distributed network. Neuroimage 14, 947-958.

[28] Immisch I, Waldvogel D, van Gelderen P, Hallett M (2001) The role of the medial wall and its anatomical variations for bimanual antiphase and in-phase movements. Neuroimage 14, 674-684.

[29] Potgieser ARE, de Jong BM, Wagemakers M, Hoving EW, Groen RJM (2014) Insights from the supplementary motor area syndrome in balancing movement initiation and inhibition. Front Hum Neurosci 8, 1-11.

[30] Stephan KM, Binkofski F, Halsband U, Dohle C, Wunderlich G, Schnitzler A, Tass P, Posse S, Herzog H, Sturm V, Zilles K, Seitz RJ, Freund H (1999) The role of ventral medial wall motor areas in bimanual co-ordination A combined lesion and activation study. Brain 122, 351-368.

[31] Weersink JB, Maurits NM, de Jong BM (2019) EEG time-frequency analysis provides arguments for arm swing support in human gait control. Gait Posture 70, 71-78.

[32] Weersink JB, Eikelboom C, Dominguez Vega ZT, Maurits NM, de Jong BM (2018) Forward arm extension as a cue for gait initiation in Parkinson's patients. Mov Disord 33, 1826-1827.

[33] Makeig S, Gramann K, Jung TP, Sejnowski TJ, Poizner $\mathrm{H}$ (2009) Linking brain, mind and behavior. Int J Psychophysiol 73, 95-100.

[34] Gwin JT, Gramann K, Makeig S, Ferris DP (2010) Removal of movement artifact from high-density EEG recorded during walking and running. J Neurophysiol 103, 3526-3534.

[35] Wagner J, Solis-Escalante T, Grieshofer P, Neuper C, Müller-Putz GR, Scherer R (2012) Level of participation in robotic-assisted treadmill walking modulates midline sensorimotor EEG rhythms in able-bodied subjects. Neuroimage 63, 1203-1211.

[36] Presacco A, Goodman R, Forrester L, Contreras-Vidal JL (2011) Neural decoding of treadmill walking from non- invasive electroencephalographic signals. J Neurophysiol 106, 1875-1887.

[37] Makeig S (1993) Auditory event-related dynamics of the EEG spectrum and effects of exposure to tones. Electroencephalogr Clin Neurophysiol 86, 283-293.

[38] Engel AK, Fries P (2010) Beta-band oscillationssignalling the status quo? Curr Opin Neurobiol 20, 156-165.

[39] Gross J, Pollok B, Dirks M, Timmermann L, Butz M, Schnitzler A (2005) Task-dependent oscillations during unimanual and bimanual movements in the human primary motor cortex and SMA studied with magnetoencephalography. Neuroimage 26, 91-98.

[40] Pfurtscheller G, Lopes da Silva FH (1999) Event-related EEG/MEG synchronization and desynchronization: Basic principles. Clin Neurophysiol 110, 1842-1857.

[41] Brown P (2006) Bad oscillations in Parkinson's disease. J Neural Transm 70, 27-30.

[42] Heinrichs-graham E, Wilson TW, Santamaria PM, Heithoff SK, Torres-russotto D, Hutter-saunders JAL, Estes KA, Meza JL, Mosley RL, Gendelman HE (2014) Neuromagnetic evidence of abnormal movement-related beta desynchronization in Parkinson's disease. Cereb Cortex 24, 2669-2678.

[43] Pfurtscheller G, Zalaudek K, Neuper C (1998) Eventrelated beta synchronization after wrist, finger and thumb movement. Electroencephalogr Clin Neurophysiol 109, 154-160.

[44] Pollok B, Krause V, Martsch W, Wach C, Schnitzler A (2012) Motor-cortical oscillations in early stages of Parkinson's disease. J Physiol 13, 3203-3212.

[45] Cole SR, Meij R Van Der, Peterson EJ, Hemptinne C De, Starr XA, Voytek XB (2017) Nonsinusoidal beta oscillations reflect cortical pathophysiology in Parkinson's disease. J Neurosci 37, 4830-4840.

[46] Behrman AL, Teitelbaum P, Cauraugh JH (1998) Verbal instructional sets to normalise the temporal and spatial gait variables in Parkinson's disease. J Neurol Neurosurg Psychiatry 65, 580-582.

[47] Zampier VC, Vitório R, Beretta VS, Jaimes DAR, OrcioliSilva D, Santos PCR, Gobbi LTB (2018) Gait bradykinesia and hypometria decrease as arm swing frequency and amplitude increase. Neurosci Lett 687, 248-252.

[48] Mann RA, Hagy JL, White V, Liddell D (1979) The initiation of gait. J Bone Jt Surg 61, 232-239.

[49] Yiou E, Caderby T, Delafontaine A, Fourcade P, Honeine J (2017) Balance control during gait initiation: State-of-theart and research perspectives. World J Orthop 8, 815-828.

[50] Carpinella I, Crenna P, Calabrese E, Rabuffetti M, Mazzoleni P, Nemni R, Ferrarin M (2007) Locomotor function in the early stage of Parkinson's disease. IEEE Trans Neural Syst Rehabil Eng 15, 543-551.

[51] Dibble LE, Nicholson DE, Shultz B, Macwilliams BA, Marcus RL, Moncur C (2004) Sensory cueing effects on maximal speed gait initiation in persons with Parkinson's disease and healthy elders. Gait Posture 19, 215-225.

[52] Halliday SE, Winter DA, Frank JS, Patla AE, Ontario NLG (1998) The initiation of gait in young, elderly, and Parkinson's disease subjects. Gait Posture 8, 8-14.

[53] Hass C, Waddell D, Wolf S, Juncos J, Gregor R (2010) Gait initiation in older adults with postural instability. Clin Biomech 23, 743-753.

[54] Gantchev N, Viallet F, Aurenty R, Massion J (1996) Impairment of posturo-kinetic co-ordination during initiation of forward oriented stepping movements in 
parkinsonian patients. Electroencephalogr Clin Neurophysiol 101, 110-20.

[55] Hiraoka K, Matuo Y, Iwata A, Onishi T, Abe K (2006) The effects of external cues on ankle control during gait initiation in Parkinson's disease. Parkinsonism Relat Disord 12, 97-102.

[56] Okada Y, Fukumoto T, Takatori K, Nagino K, Hiraoka K (2011) Abnormalities of the first three steps of gait initiation in patients with Parkinson's disease with freezing of gait. Parkinsons Dis 2011, 202937.

[57] Punt M, Bruijn SM, Wittink H, Diee JH Van (2015) Effect of arm swing strategy on local dynamic stability of human gait. Gait Posture 41, 504-509.

[58] Seeber M, Scherer R, Wagner J, Solis-Escalante T, MüllerPutz GR (2014) EEG beta suppression and low gamma modulation are different elements of human upright walking. Front Hum Neurosci 8, 1-9.

[59] Seeber M, Scherer R, Wagner J, Solis-Escalante T, Müller-Putz GR (2015) High and low gamma EEG oscillations in central sensorimotor areas are conversely modulated during the human gait cycle. Neuroimage 112, 318-326.

[60] Artoni F, Fanciullacci C, Bertolucci F, Panarese A, Makeig S, Micera S, Chisari C (2017) Unidirectional brain to muscle connectivity reveals motor cortex control of leg muscles during stereotyped walking. Neuroimage 159, 403-416.

[61] Farrell BJ, Bulgakova M a, Beloozerova IN, Sirota MG, Prilutsky BI (2014) Body stability and muscle and motor cortex activity during walking with wide stance. J Neurophysiol 112, 504-524.

[62] He SQ, Dum RP, Strick PL (1995) Topographic organization of corticospinal projections from the frontal lobe: Motor areas on the medial surface of the hemisphere. $J$ Neurosci 15, 3284-3306.

[63] Iglesias C, Lourenco G, Marchand-pauvert V (2012) Weak motor cortex contribution to the quadriceps activity during human walking. Gait Posture 35, 360-366.

[64] Maier MA, Armand J, Kirkwood PA, Yang HW, Davis JN, Lemon RN (2002) Differences in corticospinal projection from primary motor cortex and supplementary motor area to macaque upper limb motoneurons: An anatomical and electrophysiological study. Cereb Cortex 12, 281-296.

[65] Petersen TH, Willerslev-Olsen M, Conway BA, Nielsen JB (2012) Motor cortex drives the muscles during walking in human subjects. J Physiol 10, 2443-2452.

[66] Vaalto S, Säisänen L, Könönen M, Julkunen P, Hukkanen T, Määttä S, Karhu J (2011) Corticospinal output and cortical excitation inhibition balance in distal hand muscle representations in nonprimary motor area. Hum Brain Mapp 32, 1692-1703.

[67] Wagner J, Solis-Escalante T, Scherer R, Neuper C, MüllerPutz G (2014) It's how you get there: Walking down a virtual alley activates premotor and parietal areas. Front Hum Neurosci 8, 93.

[68] Rouiller EM (1994) Transcallosal connections of the distal forelimb representations of the primary and supplementary motor cortical areas in macaque monkeys. Exp Brain Res 102, 227-243.

[69] Ruddy KL, Leemans A, Carson RG (2017) Transcallosal connectivity of the human cortical motor network. Brain Struct Funct 222, 1243-1252.

[70] Serrien DJ (2008) The neural dynamics of timed motor tasks: Evidence from a synchronization-continuation paradigm. Eur J Neurosci 27, 1553-1560.
[71] Jacobs JV, Horak FB (2007) Cortical control of postural responses. J Neural Transm 114, 1339-1348.

[72] Cunnington R, Windischberger C, Deecke L, Moser E (2003) The preparation and readiness for voluntary movement: A high-field event-related fMRI study of the Bereitschafts-BOLD response. Neuroimage 20, 404-412.

[73] Deecke L, Kornhuber HH (1978) An electrical sign of participation of the mesial' supplementary' motor cortex in human voluntary finger movement. Brain Res $\mathbf{1 5 9}$, 473-476.

[74] Malouin F, Richards CL, Jackson PL, Dumas F, Doyon J (2003) Brain activations during motor imagery of locomotor-related tasks: A PET study. Hum Brain Mapp 62, 47-62.

[75] Richard A, van Hamme A, Drevelle X, Golmard JL, Meunier S, Welter ML (2017) Contribution of the supplementary motor area and the cerebellum to the anticipatory postural adjustments and execution phases of human gait initiation. Neuroscience 358, 181-189.

[76] Tanji J (2001) Sequential organization of multiple movements: Involvement of cortical motor areas. Ann Rev Neurosci 24, 631-651.

[77] Jacobs JV, Lou JS, Kraakevik JA, Horak FB (2009) The supplementary motor area contributes to the timing of the anticipatory postural adjustment during step initiation in participants with and without Parkinson's disease. Neuroscience 164, 877-885.

[78] Sabatini U, Boulanouar K, Fabre N, Martin F, Carel C, Colonnese C, Bozzao L, Berry I, Montastruc JL, Chollet F, Rascol O (2000) Cortical motor reorganization in akinetic patients with Parkinson's disease: A functional MRI study. Brain 123, 394-403.

[79] Gilat M, Dijkstra BW, D'Cruz N, Nieuwboer A, Lewis SJG (2019) Functional MRI to study gait impairment in Parkinson's disease: A systematic review and exploratory ALE meta-analysis. Curr Neurol Neurosci Rep 19, 19-49.

[80] Annett M (1970) A classification of hand preference by association analysis. Br J Psychol 61, 303-321.

[81] Sejdic E, Lowry KA, Bellanca J, Perera S, Redfern MS, Brach JS (2016) Extraction of stride events from gait accelerometry during treadmill walking. IEEE $J$ Transl Eng Health Med 4, 1-11.

[82] Sayeed T, Samà A, Català A, Cabestany J (2013) Comparison and adaptation of step length and gait speed estimators from single belt worn accelerometer positioned on lateral side of the body. Intelligent Signal Processing (WISP), 2013 IEEE 8th International Symposium, pp. 14-20.

[83] Bell AJ, Sejnowski TJ (1995) An informationmaximization approach to blind separation and blind deconvolution. Neural Comput 7, 1129-59.

[84] Gwin JT, Gramann K, Makeig S, Ferris DP (2011) Electrocortical activity is coupled to gait cycle phase during treadmill walking. Neuroimage 54, 1289-1296.

[85] Jung TP, Makeig S, Westerfield M, Townsend J, Courchesne E, Sejnowski TJ (2000) Removal of eye activity artifacts from visual event-related potentials in normal and clinical subjects. Clin. Neurophysiol 111, 1745-1758.

[86] Jung TP, Makeig S, Humphries C, Lee TW, Mckeown MJ, Iragui V, Sejnowski TJ (2000) Removing electroencephalographic artifacts by blind source separation. Psychophysiology 37, 163-178.

[87] Castermans T, Duvinage M, Cheron G, Dutoit T (2014) About the cortical origin of the low-delta and high-gamma rhythms observed in EEG signals during treadmill walking. Neurosci Lett 561, 166-170. 
[88] Kline JE, Huang HJ, Snyder KL, Ferris DP (2015) Isolating gait-related movement artifacts in eeg during human walking. J Neural Eng 12, 046022.

[89] Delorme A, Makeig S (2004) EEGLAB: An open source toolbox for analysis of single-trial EEG dynamics including independent component analysis. J Neurosci Methods 134, 9-21.

[90] Benjamini Y, Hochberg Y (1995) Controlling the false discovery rate: A practical and powerful approach to multiple testing. J R Stat Soc 57, 289-300.

[91] Benjamini Y, Yekutieli D (2001) The control of the false discovery rate in multiple testing under dependency. Ann Stat 29, 1165-1188

[92] Wagner J, Makeig S, Gola M, Neuper C, Müller-Putz G (2016) Distinct $\beta$ band oscillatory networks subserving motor and cognitive control during gait adaptation. $J$ Neurosci 36, 2212-2226.

[93] Weinberger M, Mahant N, Hutchison WD, Lozano AM, Moro E, Hodaie M, Lang AE, Dostrovsky JO (2006) Beta oscillatory activity in the subthalamic nucleus and its relation to dopaminergic response in Parkinson's disease. $J$ Neurophysiol 96, 3248-3256.

[94] Beudel M, Sadnicka A, Edwards M, de Jong BM (2019) Linking pathological oscillations with altered temporal processing in parkinsons disease: Neurophysiological mechanisms and implications for neuromodulation. Front Neurol 10, 1-8.

[95] Bichsel O, Gassert R, Stieglitz L, Uhl M, Baumannvogel $\mathrm{H}$, Waldvogel $\mathrm{D}$, Baumann $\mathrm{CR}$, Imbach $\mathrm{LL}$ (2018) Functionally separated networks for self-paced and externally-cued motor execution in Parkinson's disease: Evidence from deep brain recordings in humans. Neuroimage 177, 20-29.

[96] Kuhn AA, Williams D, Kupsch A, Limousin P, Hariz M, Ku AA, Schneider G, Yarrow K, Brown P (2004) Event-related beta desynchronization in human subthalamic nucleus correlates with motor performance. Brain 127, 735-746.

[97] Sarma S V, Cheng ML, Eden U, Williams Z, Brown EN, Eskandar E (2012) The effects of cues on neurons in the basal ganglia in Parkinson's disease. Front Integr Neurosci 6, 1-12.

[98] Handojoseno AM, Gilat M, Ly QT, Chamtie H, Shine JM, Nguyen TN, Tran Y, Lewis SJG, Nguyen H (2015) An EEG study of turning freeze in Parkinson's disease patients: The alteration of brain dynamic on the motor and visual cortex. Conf Proc IEEE Eng Med Biol Soc 2015, 6618-6621.

[99] Shine JM, Handojoseno AMA, Nguyen TN, Naismith SL, Nguyen HT, Lewis SJG (2014) Abnormal patterns of theta frequency oscillations during the temporal evolution of freezing of gait in Parkinson's disease. Clin Neurophysiol 125, 569-576.

[100] Cavanagh JF, Zambrano-Vazquez L, Allen JJB (2013) Theta lingua franca: A common mid-frontal substrate for action monitoring processes. Psychophysiology 49, 220-238.

[101] Fumagalli M, Giannicola G, Rosa M, Marceglia S, Lucchiari C, Mrakic-sposta S, Servello D, Porta M, Sassi M, Zangaglia R, Franzini A, Albanese A, Romito L, Piacentini S, Zago S, Barbieri S, Priori A, Lucchiari C, Mrakic-sposta S, Servello D, Pacchetti C, Sassi M, Zangaglia R, Franzini A, Albanese A, Romito L, Piacentini S, Zago S, Pravettoni G, Barbieri S, Priori A, Fumagalli M, Giannicola G, Rosa M, Marceglia S, Lucchiari
C, Mrakic-sposta S, Servello D, Pacchetti C, Porta M, Sassi M, Zangaglia R, Franzini A, Albanese A, Romito L, Piacentini S, Zago S, Pravettoni G, Barbieri S, Priori A (2011) Conflict-dependent dynamic of subthalamic nucleus oscillations during moral decisions. Soc Neurosci 0919, 243-256.

[102] Martens KAE, Pieruccini-faria F, Almeida QJ (2013) Could sensory mechanisms be a core factor that underlies freezing of gait in Parkinson's disease? PLoS One 8, e62602.

[103] Bloem BR, Grimbergen YAM, van Dijk JG, Munneke M (2006) The "posture second" strategy: A review of wrong priorities in Parkinson's disease. J Neurol Sci $\mathbf{2 4 8}$, 196-204.

[104] Cohen RG, Klein KA, Nomura M, Fleming M, Mancini M, Filadi N, Nutt JG, Horak FB (2014) Inhibition, executive function and freezing of gait. J Parkinsons Dis 4, 111-122.

[105] Nanhoe-Mahabier W, Delval A, Snijders AH, Weerdesteyn V, Overeem S, Bloem BR (2012) The atypical subthalamic nucleus - an anatomical variant relevant for stereotactic targeting. Mov Disord 27, 544-578.

[106] Distler M, Schlachetzki JCM, Kohl Z, Winkler J, Schenk $\mathrm{T}$ (2016) Paradoxical kinesia in Parkinson's disease revisited: Anticipation of temporal constraints is critical. Neuropsychologia 86, 38-44.

[107] Vale TC, Pedroso JL, Barsottini OG, Lees AJ (2014) A Brazilian football player still on the pitch after 10 years of Parkinson's disease with severe freezing of gait. Mov Disord Clin Pract 2, 43-44.

[108] Kikuchi A, Baba T, Hasegawa T, Sugeno N (2014) Improvement of freezing of gait in patients with Parkinson's disease by imagining bicycling. Case Rep Neurol 8574, 92-95.

[109] Morris ME, Iansek R, Matyas TA, Summers JJ (1996) Stride length regulation in Parkinson's disease Normalization strategies and underlying mechanisms. Brain 119, 551-568.

[110] Morris ME (1995) Motor control considerations for the rehabilitation of gait in parkinson's disease. Mot Control Sens Mot Integr 111, 61-93.

[111] Nonnekes J, Růžička E, Nieuwboer A, Hallett M, Fasano A, Bloem BR (2019) Compensation strategies for gait impairments in parkinson disease: A review. JAMA Neurol 76, 718-725.

[112] Arya KN, Pandian S (2014) Interlimb neural coupling: Implications for poststroke hemiparesis. Ann Phys Rehabil Med 57, 9-10.

[113] Dietz V (2002) Do human bipeds use quadrupedal coordination? Trends Neurosci. 25, 462-467.

[114] Dietz V (2009) Body weight supported gait training: From laboratory to clinical setting. Brain Res Bull 78, 1-6.

[115] Lin CC, Creath RA, Rogers MW (2016) Variability of anticipatory postural adjustments during gait initiation in individuals with Parkinson disease. J Neurol Phys Ther 40, 40-46.

[116] Jacobs JV, Nutt JG, Carlson-Kuhta P, Stephens M, Horak FB (2009) Knee trembling during freezing of gait represents multiple anticipatory postural adjustments. Exp Neurol 215, 334-341.

[117] Schlenstedt C, Mancini M, Nutt J, Hiller AP, Maetzler W, Deuschl G, Horak F (2018) Are hypometric anticipatory postural adjustments contributing to freezing of gait in Parkinson's disease? Front Aging Neurosci 10, $1-9$. 
[118] Storzer L, Butz M, Hirschmann J, Abbasi O, Gratkowski M, Saupe D, Schnitzler A, Dalal SS (2016) Bicycling and walking are associated with different cortical oscillatory dynamics. Front Hum Neurosci 10, 1-12.

[119] Fischer P, Chen CC, Chang YJ, Yeh CH, Pogosyan A, Herz DM, Cheeran B, Green AL, Aziz TZ, Hyam J, Little S, Foltynie T, Limousin P, Zrinzo L, Hasegawa H, Samuel M, Ashkan K, Brown P, Tan H (2018) Alternating modulation of subthalamic nucleus beta oscillations during stepping. J Neurosci 38, 5111-5121.

[120] Bradford JC, Lukos JR, Ferris DP (2016) Electrocortical activity distinguishes between uphill and level walking in humans. J Neurophysiol 115, 958-966.
[121] Bulea TC, Kim J, Damiano DL, Stanley CJ, Park H (2015) Prefrontal, posterior parietal and sensorimotor network activity underlying speed control during walking. Front Neuroanat 9, 247.

[122] Sipp AR, Gwin JT, Makeig S, Ferris DP (2013) Loss of balance during balance beam walking elicits a multifocal theta band electrocortical response. J Neurophysiol 110, 2050-2060. 